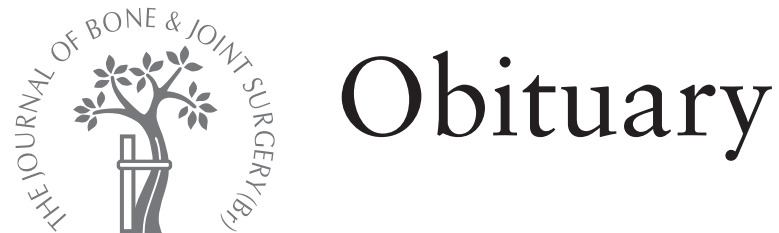

(C)2007 British Editorial Society of Bone and Joint Surgery

doi:10.1302/0301-620X.89B10.20124\$2.00

J Bone Joint Surg [Br] 2007;89-B:1407.

\section{Professor Frantz Langlais (1942 - 2007)}

The accidental death of Frantz Langlais on June 15, 2007, as he was driving home from a postgraduate teaching session for young orthopaedic surgeons in La Baule, West France, came as a shock to the European orthopaedic community, which was left to mourn for one of its most prominent members.

Frantz was a native Breton, born in 1942 in Plouër sur Rance, a small town in Brittany, where his father was a general practitioner. The essential part of his orthopaedic training was in Paris under such notable figures as Robert Merle d'Aubigné, Jean Gossett and Michel Postel, following which he joined the University Hospital of Rennes where he was appointed Chairman of the Orthopaedic and Trauma department in 1983. Over the ensuing years, he built up a remarkable team of academic surgeons by encouraging younger colleagues to develop specialised areas, such as bone banking and the use of bone allografts, arthroscopic surgery and microsurgery. His clinical activity was mostly related to arthroplasty of the hip and knee, particularly revision arthroplasty, and also to oncological surgery and allografts, but his scientific curiosity left no field unexplored. This is reflected by the list of his publications in French or English language journals, which exceeded 300 in number, adding to more than 350 communications at national or international meetings, or as a lecturer or visiting professor in more than 40 countries. He was in charge of the Laboratory of Experimental Surgery at the University of Rennes, where he was also the Scientific Director of the "Biomaterials and Biomechanics" Laboratory.

Frantz was an active member of numerous French and international scientific associations, such as the International Hip Society, the French, European and North American Societies for orthopaedic oncology (GETO, EMSOS, MSTS) and orthopaedic research (GRECO, EORS, ORS). He had been the President of the International Society of Limb Salvage (ISOLS) in 1989 and of the European Association for Musculoskeletal Transplantation (EAMST) in 1992. He was also a member of the French Académie de Chirurgie and Académie Nationale de Médecine, and was made a Fellow of the Royal College of Surgeons (FRCS Engl) in 2004. He was a reviewer or a member of the

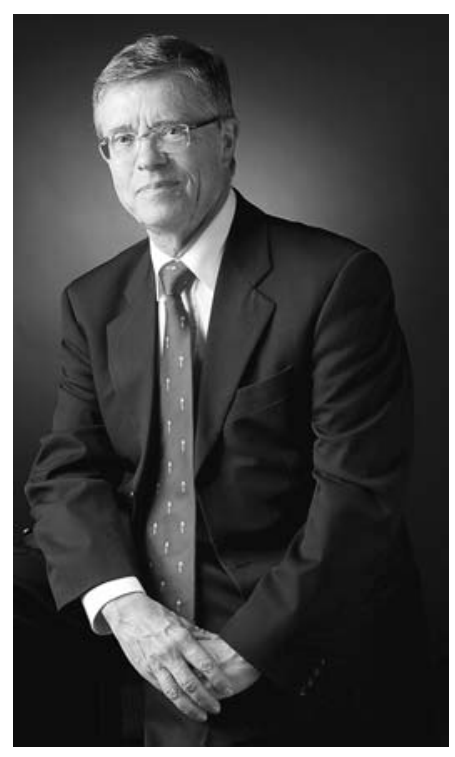

Editorial Board of several orthopaedic journals. Frantz was the President-elect of the French Orthopaedic association (SOFCOT) for 2008, a tribute to his long-standing dedication to the French orthopaedic community. He was also deeply involved in EFORT, the European Federation of National Orthopaedic and Trauma Associations, in which he served for several years as General Secretary, then as Vice-President; he was to come into office as President in January 2008. He had been instrumental in preparing the 2008 EFORT scientific meeting in Nice.

Frantz combined relentless energy with a charming personality which made him a wonderful companion; he had a bright intelligence and enjoyed discussions on any philosophical, historical or artistic topic. He had characteristic old-fashioned French courtesy and, above all, was a wholly straightforward, easy, open and loyal colleague. This rare combination of qualities made him unique. All those who were fortunate enough to have known him and to have shared his friendship will miss him desperately.

$\mathrm{He}$ is survived by his wife Mireille and their two sons Jonathan and Stéphane, none of whom were prepared for his untimely passing and whose sorrow and disarray we share.

Professor R. Lemaire EFORT Editorial Secretary 